\title{
Self-Concept in Relation to Achievement Motivation of High School Students
}

\author{
Ayesha Khan ${ }^{1}$, Dr Shah Alam ${ }^{2}$
}

\section{ABSTRACT:}

The purpose of this investigation was to find out the significant relationship between Selfconcept and achievement motivation of high school students and also tried to measure the selfconcept and achievement motivation in relation to gender. For the purpose of the present study 400 (200 boys, 200 girls) students of high school were selected randomly from four different schools of Aligarh (UP) within the age range of 16-17 years. To assess the self concept of high school students Self-Concept Questionnaire developed by Dr. R. K. Saraswat (1984) was used which provides six dimensions viz. physical, social, intellectual, moral, educational, and temperamental as well as a total self-concept score. The achievement motivation of high school students was measured by the Achievement Motivation (n-Ach) Scale developed by Dr. Pratibha Deo and Asha Mohan (1985). Pearson's product moment co-efficient correlation was applied to investigate the relationship between self-concept and achievement motivation; t-test was applied to see the differences between mean scores of girls and boys on self-concept and achievement motivation. One of the findings of the study showed a significant positive correlation existed between self concept and achievement motivation of high school students. Another finding of the study revealed that there was no significant gender differences existed on total self-concept, physical self-concept, intellectual self-concept, educational self-concept and temperamental selfconcept. Furthermore it was found that girls and boys differed significantly on social selfconcept and moral self-concept.

Keywords: Self-concept, Achievement Motivation, High School Students.

High school education stage plays a significant role in the quest to develop the nation's future manpower for rapid development Quist (2003). High school education is the foundation for higher education. It becomes indispensable to develop human resource from the early stages of human life. Over the years, behavioural scientists have noticed that some people have an intense desire for achievement of something, while others may not concern about their achievements.

\footnotetext{
${ }^{1}$ Research Scholar- Department of Psychology, A.M.U, Aligarh

${ }^{2}$ Associate Professor- Department of Psychology, A.M.U, Aligarh
} 
This phenomenon has attracted a lot of discussions and debates. It has been observed that people with a high level of achievement motivation exhibit certain characteristics. Motivating students to learn in school, colleges have become a topic of great concern for educationist and psychologists today. Lack of motivation is a big barrier in learning and a pertinent cause in the deterioration of educational standards. According to Deci and Ryan (2000) motivation is greatly appreciated because of the consequences it produces. Therefore, correlates to achievement motivation draw the attention of researchers. The attitude that is often used in conjunction with motivation to achieve is self concept, or the way one thinks about oneself to perform a task successfully. Self-concept is such a psycho-social variable which is considered to be responsible for motivation to achieve. There is considerable evidence to support the contention that a positive academic self-concept contributes to academic achievement by enhancing the motivation to achieve. A positive self-concept may contribute to good achievement motivation by student's optimistic personal expectations about himself or herself. As Franken (1994) stated that "there is a great deal of research which shows that the self-concept is, perhaps, the basis for all motivated behavior. It is the self-concept that gives rise to possible selves, and it is possible selves that create the motivation for behaviour." Research has supported the belief that there is a persistent and significant relationship between self-concept and academic achievement, and the change in one seems to be associated with a change in other (Marsh 1992; Marsh and Craven, 1997). The self-concept of the students can be influenced by certain factors. It can be due to the teachers' attitude toward them or the way their parents treat them. These factors can influence the self concept of students either in positive way or in negative way. Positive or negative self concept of students may greatly affect their motive to achieve.

The students of high school belong to adolescence stage of human span of life. World Health Organization (1997) defined adolescence is being between the ages of 10-19 years. Adolescence is a time of rapid biological change, personal development, social interactions, social expectations, and peer influence. Adolescence is a transitional period and it is the bridge between childhood and adulthood. It is the time of rapid development of growing to sexual maturity, defining personal value, finding one's vocational and social direction and discovering one's real self. Adolescence is the period of time when the surge of life reaches its highest peak (Jersild, 1963). The National Council of Educational Research and Training (1999) defined adolescence as a period of physical, psychological and social maturity from childhood to adulthood. Psychologists have described adolescence as a period of "storm and stress" a period of dramatic ups and downs through which every teenager must pass in order to develop into a mature adult. Thus, the most difficult developmental period is probably adolescence period. Today's adolescents have to face various demands and expectations from parents and teachers as well as high competition, that appear to be numerous and complex. Meeting demands at home, school and maintaining a good social relationship can contribute to a significant amount of stress. Adolescents' success in their educational endeavours and their general socio-emotional adjustments are influenced by a variety of personal characteristics and environmental experiences. As a child goes through adolescence, he or she is subjected to many different 
psychological and social challenges, stressors, and opportunities. An important factor in handling these challenges is a positive self concept. The development of a positive self-concept during adolescence period is very necessary for healthy personality development.

\section{SELF-CONCEPT}

Self-concept is an organisation of beliefs about the self. Self-concept is individuals' overall perception of their abilities, behaviour and personality. Self-concept is one of the most popular ideas in psychological and educational literature which is considered as a key to success. It shapes how the individual views his relations with the world and reflects his overall quality of being. The self-concept is basically a set of ideas about oneself: who you are as a person, and your place in the world, society, and the lives of people around you. Self concept is an important phenomenon for a healthy and sound personality of an individual. Raimy (1943) was the first person who defined the self-concept, "the self-concept is the more or less organized perceptual object resulting from present and past self observation... (i.e.,) what a person believes about himself. The self-concept is the map which each person consults in order to understand himself, especially during moment of crises or choice". Hattie (1992) viewed self-concept in terms of the cognitive appraisal one makes of the expectations, descriptions, and perceptions that one holds about one's self. The success and failure of one is largely dependent upon one's perceptions of him/her and what others think of him or her. It is dynamic, unique, and always evolving. No person is born with a self-concept. Self-concept develops as a person grows old. It means that our perceptions towards our selves can be shaped, reshaped, and can also be affected by environmental factors. Self concept develops through interaction with people and environment. As pointed out by Gerger (1955) social interaction does such for this i.e. to understand himself and to guide his conduct. These interactions continue to affect self concept. In the words of Sood (2006) self-concept is the sum total of person's perceptions about his /her physical, social, temperamental and academic competence. It covers beliefs, convictions and values the person holds.

\section{ACHIEVEMENT MOTIVATION}

Motivation is the basic drive for all of our actions. Motivation refers to the dynamics of our behaviour, which involves our needs, desires, and ambitions in life. The motivation that produces a need for better success or achievement is called achievement motivation. Achievement motivation is relatively a new concept in the world of Motivation. Achievement motive is a concept developed by the social psychologist McClelland to denote the strong urge felt by an individual or society for achievement in various aspects like education, culture, money, etc. that satisfies the need of self-esteem. McClelland et al (1959) defined achievement motivation as a competition with a standard of excellence. Thus the achievement motivation is characterized by a desire to attain a high standard of excellence and to accomplish the unique objective. Atkinson and Feather (1966) stated that "Achievement motive is conceived as a latest disposition which is manifested in overt striving only when the individual perceives performance as instrumental to a sense of personal accomplishment". Achievement motivation can be defined as an individual's 
need to meet realistic goals, receive feedback and experience a sense of accomplishment. People who are oriented towards achievement, in general, enjoy life and feel in control. Being motivated keeps people dynamic and gives them self-respect. Achievement motivation has been defined as the extent to which individuals differ in their need to strive to attain rewards, such as physical satisfaction, praise from others and feelings of personal mastery (McClelland, 1985).

Weiner (1986) in his achievement motivation and emotion theory states that achievement motivation deals with success and failure, causal thinking, and emotional thinking of achievement behaviour. Individuals with high achievement motives will act in such a ways that will help them to outperform others, meet or surpass some standard of excellence, or do something unique (Schmidt \& Frieze, 1997, 427). Achievement goals can affect the way an individual performs a task and represent a desire to show competence (Harackiewicz, Barron, Carter, Lehto, \& Elliot, 1997). Achievement motivation is considered as intrinsic motivation of an individual that concerned with work planning, pattern of actions and a self-feeling to achieve success at the standard of excellence. Gesinde (2000) stated that achievement motivation is a self-determinant to academic success. Therefore the achievement motivation is based on reaching success and achieving all of our aspirations in life.

\section{REVIEW OF RELATED LITERATURE}

Clark and Seevers (2003) conducted a study to investigate the relationship between student selfconcept, both in a global sense and more specific areas, with achievement scores in reading and mathematics. Student self-concept was assessed with the Piers-Harris Children's Self-Concept Scale and academic achievement was measured by the Texas Assessment of Academic Skills annual test battery. Results indicated a significant positive correlation between global selfconcept and reading achievement and a weaker positive correlation for mathematics achievement.

Bester (2007) conducted a study on personality development of the adolescent peer versus parents. The sample chosen were 53 boys and 55 girls. The respondents completed Fourje's (2001) self concept scale, and it was found that there was no gender difference in boys' and girls' self concept.

Awan et al (2011) made a study on relationship between achievement motivation, self concept and achievement in English and mathematics at secondary level and found that self concept has a significant relationship with achievement motivation.

Khirade, Santosh K. (2012) measured self-concept among the adolescent. Sample comprised of 80 girls and 80 boys. Self concept questionnaire by Dr .Raj Kumar Saraswat was used to assess their self concept. It was also found that there was no significant difference between the self concept of boys and girls \& there was no significant difference between the physical, social, temperamental, educational, moral and Intellectual self-concept among the boys and girls adolescent students. 
Arul Lawrence and Vimala (2013) conducted a study to investigate the relationship between selfconcept and achievement motivation of high school students. Sample consisted of 250 high school students. Self-concept Questionnaire developed by Dr. Raj Kumar Saraswat and Achievement Motive Test (ACMT) developed by V.P. Bhargava (1994) were used for the collection of data. Findings of the study revealed a significant positive relationship between selfconcept and achievement motivation of high school students.

\section{OBJECTIVES}

The main objectives of this study are:

1- To find out the relationship between self concept and achievement motivation of high school students.

2- To investigate gender difference for self concept of high school students.

3- To investigate gender difference for achievement motivation of high school students.

\section{SIGNIFICANCE OF THE STUDY}

Self-concept is an important element in the growth and developmental process for individual. Various studies have shown a positive correlation between self-concept and achievement motivation. Those who have high self-concept can easily develop high level of intrinsic motivation within themselves which leads to great achievement. Achievement motivation, as it relates to students, is very important. Achievement motivation is considered as intrinsic motivation of an individual that concerned with work planning, pattern of actions and selffeeling to achieve success at the standard of excellence. Those students who have high motivation for achievement they generally do well academically. Students with low motivation do not do well academically. Students with high self-concept feel themselves competent and motivate to achieve certain goals. The basic assumption is that students who feel good about themselves and believe in their abilities are the ones who are most likely to be successful. Selfconcept is such a psycho-social variable which is considered to be responsible for motivation to achieve. Therefore the researcher desired to study the relationship between self-concept and achievement motivation of high school students.

\section{METHODOLOGY}

\section{Sample and Sampling Technique:}

To comply with the objectives of this study, 400 high school students (200-girls, 200-boys) were randomly selected from different schools of Aligarh. The age range of students was 16-17.

\section{Research Tools}

Achievement Motivation (N-Ach) Scale: In the present study the achievement motivation of high school students was measured by the Achievement Motivation (n-Ach) Scale developed by Dr. Pratibha Deo and Asha Mohan (1985). The scale consists of 50 items, 13 are negative and 37 are positive items with 5 points to rate viz Always, Frequently, Sometimes, Rarely and Never. The test-retest reliability coefficients of the scale were found to be .69 and the validity coefficient were found to be .04 
Self Concept Inventory: In order to measure self-concept Dr. Raj Kumar Saraswat Self-concept questionnaire (1984) was used. The questionnaire provides six dimensions viz. Physical, Social, Intellectual, Moral, Educational, and Temperamental as well as a Total Self-Concept score. The questionnaire consisted of 48 items. Each item is provided with five alternatives. There is no time limit for responding to all the items. Reliability of the inventory was found by test-retest method, and it was found to be .91 for the total self-concept measure. The maximum obtained score is 240 and minimum is 40 . High score on this inventory means high self-concept and low score means low self-concept.

\section{Procedure}

To obtain the data, the scale was administered to a group of high school students during their class hours. Participants were assured that their responses will be kept confidential and only the researcher would have access to their data.

\section{Statistical Analysis}

In the present study for analyzing the obtained data, the investigator has used Pearson Product Moment Correlation to find out the relationship between self-concept and achievement motivation of high school students and t-test to investigate the gender difference on self-concept and achievement motivation.

\section{RESULT \&DISCUSSION}

\section{TABLE-1: Coefficients of correlation between self-concept and achievement motivation}

$\begin{array}{lc}\text { Self-concept } & \text { Achievement } \\ \text { Physical self-concept } & .044 \\ \text { Social self-concept } & .202^{* *} \\ \text { Intellectual self-concept } & .325^{* *} \\ \text { Moral self-concept } & .362^{* *} \\ \text { Educational self-concept } & .361^{* *} \\ \text { Temperamental self-concept } & .131^{* *} \\ \text { Total self-concept } & .333^{* *}\end{array}$

$* * \mathbf{P}<0.01$ level.

Table 1 depicts correlation coefficient of self-concept and achievement motivation of high school students. It is clear from the table that total self-concept and its five dimensions viz. Social, intellectual, moral, educational and temperamental self-concept have statistically significant positive correlation with achievement motivation of high school students. Because ' $r$ ' values of social (.202), intellectual (.325), moral (.362), educational.361), temperamental (.131) and total self-concept (.333) are significant at 0.01 levels. But there is no statistically significant correlation existed between physical self-concept and achievement motivation of high school students as ' $r$ ' value (.044) is not significant. Findings of the present study that self-concept has positive relationship with achievement motivation of high school students is consistent with the findings of the study conducted by Arul Lawrence and Vimala (2013), where they found 
significant positive relationship between self-concept and achievement motivation. This finding is also in congruence with the finding of Chetri (2014) where she conducted a study on self concept and achievement motivation of adolescents and their relationship with academic achievement and found a relationship between self concept and achievement motivation. This is due to the fact that those students who have high level of self-concept can develop high level of intrinsic motivation within themselves which motivate them to achieve better. They are aware of their strengths, talents and weaknesses. This makes them able to rectify their weaknesses and develop their strengths to achieve higher in this highly competitive world.

\section{TABLE-2: gender difference on self-concept}

\begin{tabular}{lllccc} 
Variables & Gender & N & Mean & S.D & t-value \\
Physical & Male & 200 & 29.43 & 4.242 & 1.269 \\
Social & Female & 200 & 29.96 & 4.030 & \\
& Male & 200 & 28.46 & 4.717 & $2.212^{*}$ \\
Intellectual & Female & 200 & 29.41 & 3.827 & \\
& Male & 200 & 29.00 & 4.131 & .851 \\
Moral & Female & 200 & 29.32 & 3.476 & \\
\multirow{3}{*}{ Educational } & Male & 200 & 30.14 & 5.997 & $1.928^{*}$ \\
& Female & 200 & 31.16 & 4.475 & \\
Temperamental & Male & 200 & 30.44 & 4.359 & .827 \\
& Female & 200 & 30.78 & 3.844 & \\
Total self-concept & Male & 200 & 27.22 & 4.219 & 1.450 \\
& Female & 200 & 28.96 & 16.386 & \\
& Male & 200 & 174.66 & 17.241 & .655 \\
\hline
\end{tabular}

$* \mathbf{P}<0.05$ level.

Table 2 depicts the gender difference on total self-concept and its dimensions. The mean scores (29.41) of girls on social self-concept are greater than the mean scores (28.46) of boys. This clearly indicates that girls are significantly better on social self-concept than boys as t-value (2.212) is statistically significant at 0.05 level of confidence. This is due to the fact that now a day's girls are given much more importance in family and society. They spend more time with their families and relatives as compared to boys. They are more social than boys. Girls are also found to be better on moral self-concept as the mean scores (31.16) of girls are greater than the mean scores (30.14) of boys and the t-value 1.928 is statistically significant at 0.05 level of confidence. Except on these two dimensions of self-concept t-test failed to reveal a statistically reliable difference between the mean scores of girls and boys of high school on other dimensions of self-concept like physical, intellectual, educational, temperamental and on total self-concept. This finding of the present study is in congruence with finding of the study conducted by Bester (2007) and Khirade, Santosh K. (2012), where they observed no significant difference between 
boys and girls on total self-concept and its dimensions. In explaining these findings of the present study, it can be said that present age is the age of knowledge exploded society, there is gender equality almost in every field. Girls are in no way lagging behind the boys because people have started to give equal importance to the girls' education. Governments have made various policies exclusively for women. Girls are also getting equal opportunities and they occupy high positions in almost all fields.

TABLE-3: gender difference on achievement motivation

$\begin{array}{lccccc}\text { Variables } & \text { Gender } & \text { N } & \text { Mean } & \text { S.D } & \text { t-value } \\ \text { Achievement motivation } & \text { Male } & 200 & 131.80 & 21.413 & \\ & \text { Female } & 200 & 136.09 & 17.273 & 2.203^{*} \\ & & & & \end{array}$

$* \mathbf{P}<0.05$ level.

Table 3 shows gender difference on achievement motivation. It is evident from the table that girls have better achievement motivation than that of boys, as t-test reveals statistically reliable difference between the mean sores of girls $(M=136.09)$ and boys $(M=131.80)$ in their achievement. The t-value is significant at 0.05 level of confidence. This finding is in congruence with the studies conducted by Wang et al (2008), Prakash and Coplan (2007) and Kiuru et al (2009), where they found girls achieve better academically.

\section{CONCLUSION}

Correlation analysis revealed that there was a significant positive relationship between selfconcept and achievement motivation of high school students. Another findings of the study showed that girls had high social and moral self concept as compared to boys. Next findings revealed that girls and boys were not found differ significantly on their total self-concept and its four dimensions viz. physical, intellectual, educational and temperamental self-concept. It can be safely conclude that self concept has positive correlation with achievement motivation of high school students. The students of high school belong to adolescence stage of human span of life. Adolescence is a period of life in which the sense of self' changes profoundly. The adolescent self-concept is influenced by psychological and social relationships. They are conscious of their self-awareness, know that people can think about their own experiences and this leads to increased self-consciousness and a sense of control. The adolescent time period is a difficult time period when self-concept of an individual is particularly susceptible to being challenged. Therefore it becomes indispensible to take efforts to improve the self-concept of adolescents. Self-concept is very important and essential in developing a child personality. Teachers and parents should provide a good environment. Parents have to consider those factors that influence the development of more positive self-concept. This will help adolescents to develop their selfconcept which will further lead to understanding of their capabilities, strengths, weaknesses, interests, attitude, aptitude, emotions, knowledge etc. This will lead them to develop a high level 


\section{Self-Concept in Relation to Achievement Motivation of High School Students}

of achievement motivation. At school, the development of students' self-concept depends on the environment of school, behaviour of educators and relationship with friends. A positive classroom environment creates a more favourable and positive environment in which a more positive self-concept develop among students that can contribute to good academic achievement. Achievement during this period can be a stepping stone for the forthcoming year. Educators should arrange psychological grooming process and create stress free environment for the development of students self concept. Students need to improve their self confidence, beliefs, perception, attitudes, and feelings for the betterment of their self concept. An adolescent can succeed in life, only if he or she has good achievement motivation and self-concept.

\section{REFERENCES}

Arul Lawrence, A., Vimala, A. (2013). SELF-CONCEPT AND ACHIEVEMENT MOTIVATION OF HIGH SCHOOL STUDENTS. Conflux Journal of Education 2320-9305 Volume 1, Issue 1, June 2013.

Awan, et. al. (2011). A study of relationship between achievement motivation, self concept and achievement in English and mathematics at secondary level. International education studies. Vol-4 (3), pp-72-79.

Bester, G. (2007). Personality development of adolescent : peer group versus parents, South Africa. journal of Education,27(2)177-199.

Chan, P. H. (2003). Self-concept and test anxiety of high and low academic achievers in Hong Kong secondary school. Applied Social Studies- Postgraduate Diploma PapersPsychology. Retrieved from http://hdl.handle.net/2031/3550 retrived on 12 October, 2009.

Chetri, S. (2014). Self concept and achievement motivation of adolescents and their relationship with academic achievement. International journal of advancements in research \& technology. Vol-3(5), pp-236-253.

Clark, M. J., \& Seevers, R. L. (2003). The relationship between global self-concepts, specific self-concepts, and the texas assessment of academic skills achievement test. National Forum of Special Education Journal, 12(1-2), 3-11.

Franken, R. (1994). Human motivation (3rd ed.). Pacific Grove, CA: Brooks/Cole.

Gerger K. J. (1955) The concept of self, New York, Winston Inc.

Gesinde, A. M. (2000). Motivation in ZAA Omideyi (ed) Fundamental of guidance and counselling. Ibadan: Kaneda Publishers.

Harackiewicz, J. M., Barron, K. E., Carter, S. M., Lehto, A. T., \& Elliot, A. J. (1997).

Predictors and consequences of achievement goals in the college classroom:

Maintaining interest and making the grade. Journal of Personality and Social Psychology, 73, 1284-1295.

Hattie, J.B. (1992). Self-concept. Hillsdale, NJ: Lawrence Erlbaum Associates

Jersild, A.T., (1963). The psychology of adolescence, London: Collier Macmillan Ltd., The Macmillan company, pp.3, 5, 19. 
Khirade, Santosh K. (2012). A Study of Self Concepts of the Adolescents. Indian Streams Research Journal, Vol. 2 (8).Marsh, H. (1992). The content specificity of relations between academic self- concept and achievement: An extension of the Marsh/Shavelson model.

Marsh, H. W., \& Craven, R. G. (1997). Academic self-concept: Beyond the dustbowl. In G. Phye (Ed.), Handbook of classroom assessment: Learning, achievement and adjustment. US: Academic Press. (pp. 131-198). Orlando, FL: Academic Press

McClelland, D. Atkinson, J., Clark, R., \& Lowell, E (1959). The Achievement Motive, New York: Appleton-Century-Crofts.

McClelland, D. C. (1985). Human motivation. Chicago:Scott Foresman. National Council of Educational Research and Training, 1999, Adolescence Education in School: Package of Basic material, NCERT, New Delhi.

Quist H.O (2003), Secondary Education -A Tool for National Development in Ghana. A Critical Appraisal of the Post-Colonial Context. African Development, vol. III, No 3 \& 4, p.188 191

Raimy, V. (1943). The self-concept as a factor in counseling and personality organization. Unpublished doctoral dissertation, Ohio State University, Ohio.

Saraswat, R.K. (1984). Manual for Self concept questionnaire, Agra: National Psychological Corporation.

Sood, P., 2006, Educational choices in relation to academic stress, achievement motivation and academic self concept. J. Commu. Guid. Res., 23 (2)141-152.

Weiner, B. (1986). An attribution theory of motivation and emotion. New York:

Springer-Verlag. 